\title{
Mechanism of Ion-Diffusion Solid-Phase Reduction of Iron Oxides of Technogenic Origin in the Presence of the Liquid Phase and without it
}

\author{
Oleg Sheshukov ${ }^{1,2}$, Mikhail Mikheenkov ${ }^{1,2}$, Larisa Vedmid' ${ }^{1,2, *}$, Iliya Nekrasov ${ }^{1,2}$ \\ and Denis Egiazaryan 1,2 (B) \\ 1 Institute of Metallurgy of the Ural Branch of Russian Academy of Sciences, 101, Amundsen Str., \\ 620016 Ekaterinburg, Russia; o.j.sheshukov@urfu.ru (O.S.); silast@mail.ru (M.M.); ivn84@bk.ru (I.N.); \\ avari@mail.ru (D.E.) \\ 2 Ural Federal University Named after the first President of Russia B.N. Yeltsin, Mira Str. 19, \\ 620002 Ekaterinburg, Russia \\ * Correspondence: elarisa100@mail.ru; Tel.: +7-343-232-9073
}

Received: 30 September 2020; Accepted: 18 November 2020; Published: 24 November 2020

check for updates

\begin{abstract}
The processes of iron oxides' reduction have a complex physicochemical mechanism, with the participation of solid, liquid, and gaseous substances. The article discusses the existing models for the reduction of iron oxides and provides data on the thermodynamic possibility of carrying out the reactions of their reduction through the solid and gas phases. Experimental data on the reduction of iron from industrial scale, obtained by the DSC (differential scanning calorimetry) method, show the kinetic dependence of the rate and completeness of recovery on external factors: pressing pressure during sample preparation and the reagents' composition. The pressing pressure, under conditions of iron ions' solid-phase diffusion, has the significant effect by increasing the reagents' contact area. Under conditions of iron ions' comprehensive diffusion, the pressing pressure does not affect the reduction processes rate. The introduction of 10 mass.\% flux into the raw mixture composition leads to a partially liquid-phase diffusion of iron ions and weakens the effect of the pressing pressure in this process. An ion diffusion-catalytic mechanism is proposed to describe the observed effects during the reduction of iron oxide of technogenic origin.
\end{abstract}

Keywords: technogenic origin; iron oxides; thermodynamics; recovery; diffusion; metallization

\section{Introduction}

The long-term development of extractive industries in conditions of extensive nature management has led to the accumulation of a huge number of metallurgical, chemical, energy, and other technogenic formations. By now, in the locations of the largest and oldest metallurgical complexes, mineral reserves are being depleted. At the same time, accumulated technogenic formations can be a promising source of raw materials, of which iron is the most valuable for ferrous metallurgy. However, the accumulated technogenic formations at the same time are the source of environmental pollution. Involvement of technogenic formations in processing will help to solve the issues of limited resource base and environmental pollution [1-3]. Technogenic formation of the iron oxide is presented mostly by sludge and scale [3-5]. In such technogenic formations all iron oxides can be found simultaneously, and they are arranged in layers in the scale. The layered structure of the scale is completely consistent with the diagram of the iron-oxygen state. Above the temperature of $650{ }^{\circ} \mathrm{C}$, the inner layer of scale consists of wustite $(\mathrm{FeO})$, the middle layer of magnetite $\left(\mathrm{Fe}_{3} \mathrm{O}_{4}\right)$, and the outer layer of hematite $\left(\mathrm{Fe}_{2} \mathrm{O}_{3}\right)[6]$. The properties of iron oxides according to [7] are presented in Table 1. 
Table 1. Properties of Iron Oxides, data from [7].

\begin{tabular}{|c|c|c|c|c|}
\hline \multirow{2}{*}{ Index } & \multirow{2}{*}{$\mathrm{FeO}$} & \multicolumn{2}{|l|}{$\mathrm{Fe}_{2} \mathrm{O}_{3}$} & \multirow{2}{*}{$\mathrm{Fe}_{3} \mathrm{O}_{4}$} \\
\hline & & $\alpha$ & $\gamma$ & \\
\hline Color & black & From dark-red to dark-purple & brown & black \\
\hline Syngony & cubic & rhombohedral & cubic & cubic \\
\hline Lattice parameter, $\AA$ & 4.29 & $5.42 \alpha=55^{\circ} 17^{\prime}$ & 8.34 & 8.38 \\
\hline Number of formula units in a cell & 4 & 2 & - & 8 \\
\hline Space group & Fm3m & $\mathrm{R} 3 \mathrm{c}$ & $\mathrm{Fd} 3 \mathrm{~m}$ & $\mathrm{Fd} 3 \mathrm{~m}$ \\
\hline Melting point, ${ }^{\circ} \mathrm{C}$ & 1370 & 1565 & - & 1600 \\
\hline
\end{tabular}

Wustite $(\mathrm{FeO})$ is a thermodynamically unstable compound. Below the temperature of $560{ }^{\circ} \mathrm{C}$, it decays into $\alpha$ - $\mathrm{Fe}$ and magnetite $\left(\mathrm{Fe}_{3} \mathrm{O}_{4}\right)$. The crystal lattice is cubic, a $=4.29 \AA$. The wustite crystal lattice always contains an excess of oxygen, so its composition corresponds more precisely to the nonstoichiometric formula FeO1.09. As a result, the wustite crystal lattice contains a significant number of nonstoichiometry defects in the form of $\mathrm{Fe}^{2+}$ ion vacancies [8]. From a structural point of view, wustite refers to subtraction solid solutions: In its lattice, oxygen atoms occupy all the nodes in the anionic sublattice and some nodes in the cationic sublattice are not occupied by iron ions. If there is a lack of $\mathrm{Fe}^{2+}$ cations in the lattice, its electroneutrality is maintained due to the conversion of part of $\mathrm{Fe}^{2+}$ cations to $\mathrm{Fe}^{3+}$. So, this nonstoichiometric compound can be considered as a substitution solid solution of $\mathrm{Fe}_{2} \mathrm{O}_{3}$ in $\mathrm{FeO}$ [8].

Iron oxide $\alpha-\mathrm{Fe}_{2} \mathrm{O}_{3}$ (hematite) is characterized by a rhombohedral corundum-type lattice with parameters $\mathrm{a}=5.42 \AA$ and $\alpha=55^{\circ} 17^{\prime}$. The unit cell of hematite is formed by four $\mathrm{Fe}^{3+}$ and six $\mathrm{O}^{2-}$ ions, which form a dense hexagonal package. One-third of the octahedral voids are vacant and two-thirds of them are filled with $\mathrm{Fe}^{3+}$ ions [6].

Magnetite $\left(\mathrm{Fe}_{3} \mathrm{O}_{4}\right)$ has a cubic lattice of "reversed" spinel with a $=8.38 \AA$. Eight ions of $\mathrm{Fe}^{2+}$, 16 of $\mathrm{Fe}^{3+}$, and 32 of $\mathrm{O}^{2-}$ are present in the unit cell of magnetite. Oxygen ions form a dense cubic lattice containing 32 octahedral and 64 tetrahedral voids in a single unit cell. In this case eight ions of $\mathrm{Fe}^{2+}$ and the same amount of $\mathrm{Fe}^{3+}$ are distributed (statistically) in octahedral and the remaining eight $\mathrm{Fe}^{3+}$ in tetrahedral internodes. The presence of multivalent ions $\mathrm{Fe}^{2+}$ and $\mathrm{Fe}^{3+}$ in the same crystallographic positions (octahedral) facilitates the exchange of electrons and increase magnetite electrical conductivity [7].

Reduction of iron oxides in the physical and chemical aspects is considered to be heterogeneous processes, involving liquid, solid, and gaseous substances. The internal energy of the system continuously changes under the influence of both external (temperature) and internal (vapor pressure, reducing agent composition, degree of phase contact, etc.) parameters. The most important reducing agent of iron, widely used in metallurgical practice, is carbon. Several models have been proposed to describe the mechanism of metal oxides' reduction by carbon [9-13]. S.I. Popel and his colleagues proposed four recovery schemes [14]. The first scheme is based on the most frequently used two-stage recovery scheme based on the adsorption-catalytic mechanism of G.I. Chufarov [15].

According to the first scheme, it is assumed that the process is carried out as a result of two simultaneous reactions:

$$
\begin{gathered}
\mathrm{MeO}+\mathrm{CO}=\mathrm{Me}+\mathrm{CO}_{2} \uparrow \\
\mathrm{CO}_{2}+\mathrm{C}=2 \mathrm{CO} \uparrow
\end{gathered}
$$

The reduction of iron oxide in this scheme occurs through $\mathrm{CO}$, and the role of solid carbon is reduced to the regeneration of carbon oxide by the Boudoir reaction. 
According to the second (dissociative) scheme, the reduction of metals with a sufficiently high dissociation elasticity $\left(-\Delta P_{\mathrm{O}_{2}}^{0} \geq 1 \mathrm{~Pa}\right)$ can proceed by dissociation of the oxide and subsequent interaction of molecular oxygen with carbon:

$$
\begin{gathered}
\mathrm{MeO}=\mathrm{Me}+1 / 2 \mathrm{O}_{2} \uparrow \\
\mathrm{C}+1 / 2 \mathrm{O}_{2}=\mathrm{CO} \uparrow
\end{gathered}
$$

According to the third scheme, if the reduction and sublimation temperatures of the oxide are close, the interaction of the oxide and the reducing agent is possible due to the evaporation of the oxide with subsequent condensation (adsorption) of its vapors on the carbon surface, where the reduction process occurs:

$$
\begin{gathered}
\mathrm{MeOs}=\mathrm{MeO} \uparrow \\
\mathrm{MeO} \uparrow+\mathrm{Cs}=\mathrm{MeOads} \times \mathrm{Cs} \\
\mathrm{MeOads} \times \mathrm{Cs}=\mathrm{Mes} \times \mathrm{COads} \\
\mathrm{Mes} \times \mathrm{COads}=\mathrm{Mes}+\mathrm{CO} \uparrow
\end{gathered}
$$

In this way, it is possible to reduce the volatile oxides of $\mathrm{MoO}_{3}, \mathrm{WO}_{3}, \mathrm{Nb}_{2} \mathrm{O}_{3}$, etc.

According to the fourth scheme, the reduction occurs directly during contact of solid phases: the interaction of solid carbon and oxide. This is one of the limiting factors in the scheme implementation. At the beginning, this contact is direct. After formation of separating layer of metal or lower oxide, it is carried out by the diffusion of reagents through this layer. According to the authors [11], the flow of the four scheme is very possible, but its contribution to the overall kinetics of metals' direct reduction from oxides is negligible, since the actual particles' contact surface is an insignificant fraction of their total surface. The second limiting factor of the fourth scheme possibility is the diffusion of reagents, which is quite slow at low temperatures.

According to [16], all the described schemes are based on outdated provisions of the atomic-molecular theory of reduction, which represents atoms as solid indivisible balls, and does not take into account advances in the study of the fine structure of matter and physical theories describing the behavior of elementary particles that make up atoms.

\section{Thermodynamic Analysis of the Reactions of Iron Oxides' Reduction}

The total reaction of all four schemes is the Reaction (9):

$$
\mathrm{MeO}+\mathrm{C}=\mathrm{Me}+\mathrm{CO} \uparrow
$$

In relation to a specific iron oxide, this interaction is possible by the following Reactions (10)-(12):

$$
\begin{gathered}
2 \mathrm{Fe}_{2} \mathrm{O}_{3}+6 \mathrm{C}=4 \mathrm{Fe}+6 \mathrm{CO} \uparrow \\
\mathrm{Fe}_{3} \mathrm{O}_{4}+4 \mathrm{C}=3 \mathrm{Fe}+4 \mathrm{CO} \uparrow \\
\mathrm{FeO}+\mathrm{C}=\mathrm{Fe}+\mathrm{CO} \uparrow
\end{gathered}
$$

Reduction of specific iron oxides through the gas phase is possible by Reactions (13)-(15):

$$
\begin{gathered}
\mathrm{Fe}_{2} \mathrm{O}_{3}+3 \mathrm{CO}=2 \mathrm{Fe}+3 \mathrm{CO}_{2} \uparrow \\
\mathrm{Fe}_{3} \mathrm{O}_{4}+4 \mathrm{CO}=3 \mathrm{Fe}+4 \mathrm{CO}_{2} \uparrow \\
\mathrm{FeO}+\mathrm{CO}=\mathrm{Fe}+\mathrm{CO}_{2} \uparrow
\end{gathered}
$$


According to [17], when cementite is formed in the system by Reaction (16):

$$
6 \mathrm{FeO}+5 \mathrm{C}=2 \mathrm{Fe}_{3} \mathrm{C}+3 \mathrm{CO}_{2} \uparrow
$$

it is also possible to reduce iron through the gas phase by Reaction (17):

$$
\mathrm{Fe}_{3} \mathrm{C}+\mathrm{CO}_{2} \uparrow=3 \mathrm{Fe}+2 \mathrm{CO} \uparrow \text {. }
$$

Thermodynamic calculations were performed to determine the temperature range in which the reduction reactions of specific iron oxides can occur through the solid and gas phases. The results of calculating the Gibbs free energy for Reactions (11)-(18) are shown in Table 2.

Table 2. Value of Gibbs Free Energy of Iron Oxide Reduction Reactions.

\begin{tabular}{ccccccc}
\hline \multirow{2}{*}{ Reaction № } & \multicolumn{7}{c}{$\Delta \mathrm{G}^{\mathbf{0}} \mathrm{T}, \mathbf{J} / \mathbf{m o l}$, at Temperature, ${ }^{\circ} \mathbf{C}$} \\
\cline { 2 - 7 } & $\mathbf{5 0 0}$ & $\mathbf{6 0 0}$ & $\mathbf{7 0 0}$ & $\mathbf{8 0 0}$ & $\mathbf{9 0 0}$ & $\mathbf{1 0 0 0}$ \\
\hline 10 & 151.2 & 47.3 & -55.6 & -158.0 & -260.4 & -362.5 \\
\hline 11 & 136.9 & 71.1 & 6.0 & -58.9 & -123.9 & -188.8 \\
\hline 12 & 33.7 & 18.3 & 2.9 & -12.5 & -27.9 & -43.3 \\
\hline 13 & -30.3 & -29.2 & -27.7 & -26.5 & -25.4 & -24.5 \\
\hline 14 & -1.0 & 0.2 & 1.4 & 2.6 & 3.8 & 4.8 \\
\hline 15 & -1.6 & 0.7 & 2.9 & 5.0 & 7.0 & 8.9 \\
\hline 16 & 26.3 & 15.6 & 5.0 & -5.4 & -15.7 & -25.8 \\
\hline 17 & 6.8 & 3.2 & -0.4 & -4.1 & -7.9 & -11.9 \\
\hline
\end{tabular}

According to the data presented in Table 2, reduction of $\mathrm{Fe}_{2} \mathrm{O}_{3}$ oxide (Reaction (10)) by direct interaction of solid phases is thermodynamically possible starting from the temperature of $700{ }^{\circ} \mathrm{C}$, and $\mathrm{Fe}_{3} \mathrm{O}_{4}$ and $\mathrm{FeO}$ (Reactions (11) and (12)) starting from the temperature of $800{ }^{\circ} \mathrm{C}$. Through the gas phase, reduction of $\mathrm{Fe}_{2} \mathrm{O}_{3}$ (Reaction (13)) is possible in the entire temperature range (from room temperature to $1000{ }^{\circ} \mathrm{C}$ ). Above the temperature of $600{ }^{\circ} \mathrm{C}$, recovery through the gas phase of $\mathrm{Fe}_{3} \mathrm{O}_{4}$ and $\mathrm{FeO}$ (Reactions (14) and (15)) is thermodynamically impossible. Since, in accordance with the principle of sequence of transformations formulated by A.A. Baikov [18], above the temperature of $570{ }^{\circ} \mathrm{C}$, the transition from higher iron oxides to lower ones proceeds according to the scheme:

$$
\mathrm{Fe}_{2} \mathrm{O}_{3}+\mathrm{C}(\mathrm{CO}) \rightarrow \mathrm{Fe}_{3} \mathrm{O}_{4}+\mathrm{C}(\mathrm{CO}) \rightarrow \mathrm{FeO}+\mathrm{C}(\mathrm{CO}) \rightarrow \mathrm{Fe}
$$

According to the data [18] given in Table 3, the content of $\mathrm{Fe}_{2} \mathrm{O}_{3}$ in the scale at a temperature above $700{ }^{\circ} \mathrm{C}$ is insignificant, so it is very likely that above this temperature the reduction of $\mathrm{Fe}_{3} \mathrm{O}_{4}$ and $\mathrm{FeO}$ occurs only with the participation of solid carbon in the Reactions (11) and (12). Above the temperature of $700{ }^{\circ} \mathrm{C}$ through the gas phase, it is also possible to restore iron by Reaction (17), but this will only happen if cementite is formed in the system by Reaction (16).

Since above the temperature of $700{ }^{\circ} \mathrm{C}$ for $\mathrm{Fe}_{2} \mathrm{O}_{3}$ and for $\mathrm{Fe}_{3} \mathrm{O}_{4}$ and $\mathrm{FeO}$ above $800{ }^{\circ} \mathrm{C}$ the reduction reaction is thermodynamically possible through the solid phase, it is difficult to explain the high rate of iron oxides' reduction under conditions of practically no diffusion of reagents in the solid phase using the provisions of the classical atomic-molecular theory of reduction.

Under these conditions, there are only two ways to accelerate the reduction of iron oxides with carbon:

(1) In the absence of diffusion of reagents, increase the area and number of their contacts and

(2) Create conditions for favorable diffusion of reagents. 
Table 3. The Content of Iron Oxides in the Slag at Elevated Temperatures.

\begin{tabular}{cccc}
\hline \multirow{2}{*}{ Temperature, ${ }^{\circ} \mathbf{C}$} & \multicolumn{3}{c}{ Scale Oxide Content, Mass. $\%$} \\
\cline { 2 - 4 } & $\mathbf{F e O}$ & $\mathbf{F e}_{3} \mathbf{O}_{\mathbf{4}}$ & $\mathbf{F e}_{\mathbf{2}} \mathbf{O}_{3}$ \\
\hline 600 & 50 & 50 & 0 \\
\hline 700 & 98 & 2 & 0 \\
\hline 800 & 96 & 2 & 1 \\
\hline 900 & 90 & 9 & 1 \\
\hline 1000 & 95 & 4 & \\
\hline
\end{tabular}

According to [6,19], the area and number of contacts of reacting solid phases can be increased by grinding and subsequent pressing of the mixture components. In [20], the same approach was used in the example of the synthesis of nickel ferrite, zinc aluminates, and magnesium aluminates from oxides under pressure from atmospheric to $60 \mathrm{kbar}$. The observed strong acceleration of these reactions is explained by an increase in the contact area of the reacting particles and, thus, an improvement in the conditions for diffusion along the interphase surfaces.

The diffusion rate of reactants can be increased by partial destruction of their crystal lattice. This is possible due to the fluxes' introduction into the mixture of scale and carbon, which reduce the melting point of the scale, leading to the formation of local liquid-phase zones, in which the diffusion rate of reacting substances increases by several orders.

\section{Materials and Methods}

The rolling scale was used in this work as the main studied material. According to the phase analysis results, the scale contained mass. $\% 43.4 \mathrm{FeO}, 27.0 \mathrm{Fe}_{3} \mathrm{O}_{4}$, and $29.6 \mathrm{Fe}_{2} \mathrm{O}_{3}$, with a $\mathrm{Fe}_{\text {total }}$ content of 73.4. The coke was used as a reducing agent with a carbon content of 92 mass. \%. Its amount was $15 \%$ over the stoichiometric ratio. To assess the iron oxides' reduction rate, in the absence of reactants' diffusion, the raw mixture was prepared only from scale and coke. To assess the iron oxides' reduction rate, under conditions of comprehensive diffusion of reacting substances, a flux based on $\mathrm{CaO}, \mathrm{MgO}$, $\mathrm{SiO}_{2}, \mathrm{Al}_{2} \mathrm{O}_{3}, \mathrm{Na}_{2} \mathrm{O}$, and $\mathrm{CaF}_{2}$ was added to the scale and coke mix in an amount of 10 mass.\% of the scale [21]. Scale, coke, and flux were dried to a constant mass and joint grinded to a specific surface area by Blain $\approx 400 \mathrm{~m}^{2} / \mathrm{kg}$. The material mixture of scale, reducing agent, and flux prepared in this way was pressed at pressures of $0,100,200$, and $300 \mathrm{MPa}$.

Heat treatment of the pressed raw material mixture was carried out in an argon atmosphere with the removal of gas reaction products. Heating was performed to a temperature of $1200^{\circ} \mathrm{C}$. The thermal characteristics of the raw material mixture were determined during the heating process, and the phase composition of the final products was determined. The crystal phases' identification and their quantitative ratios in the products were determined using $\mathrm{X}$-ray phase analysis. The survey was carried out on an XRD-7000 diffractometer (Shimadzu), in CuK $\alpha$-radiation ( $40 \mathrm{kV}, 30 \mathrm{~mA})$, graphite monochromator, in the range of scattering angles $2 \Theta=10-70$ degree, with a step of 0.02 degree. The results were analyzed using the PDF-2 database (Release 2008 RDB 2.0804). Thermal analysis (TA) was performed using the DSC method (differential scanning calorimetry) on the STA 449 F3 Jupiter thermal analyzer (Netzsch-Geratebau $\mathrm{GmbH}$ ). The experiment was conducted in an argon atmosphere $\mathrm{Ar}$ (high purity $99.998 \%$, the volume fraction $\mathrm{CO}_{2}$ not more than $0.00002 \%$ ), the gas flow was $30 \mathrm{~mL} / \mathrm{min}$, under the condition of linear heating at a speed of $10 \% \mathrm{~min}$, and the temperature measurement error was no more than \pm 1.5 degree. $\mathrm{Al}_{2} \mathrm{O}_{3}$ crucibles with lids were used for the study. Lids were holed to improve the reaction gas exchange. The value of the endothermic effect was calculated in the software module of the device in $\mathrm{J} / \mathrm{g}$ and converted to $\mathrm{kJ} / \mathrm{mol}$ by multiplying the data of the device by the mole mass of metallic iron. 


\section{Results}

The pressing pressure influence on the reduction processes of iron oxides of technogenic origin was studied in the absence of a liquid phase (difficult ion diffusion) and with liquid phase if we used flux [21] (developed ion diffusion).

Figure 1 shows the DSC data of the material mixture without the flux addition pressed at pressures of $0,100,200$, and $300 \mathrm{MPa}$.

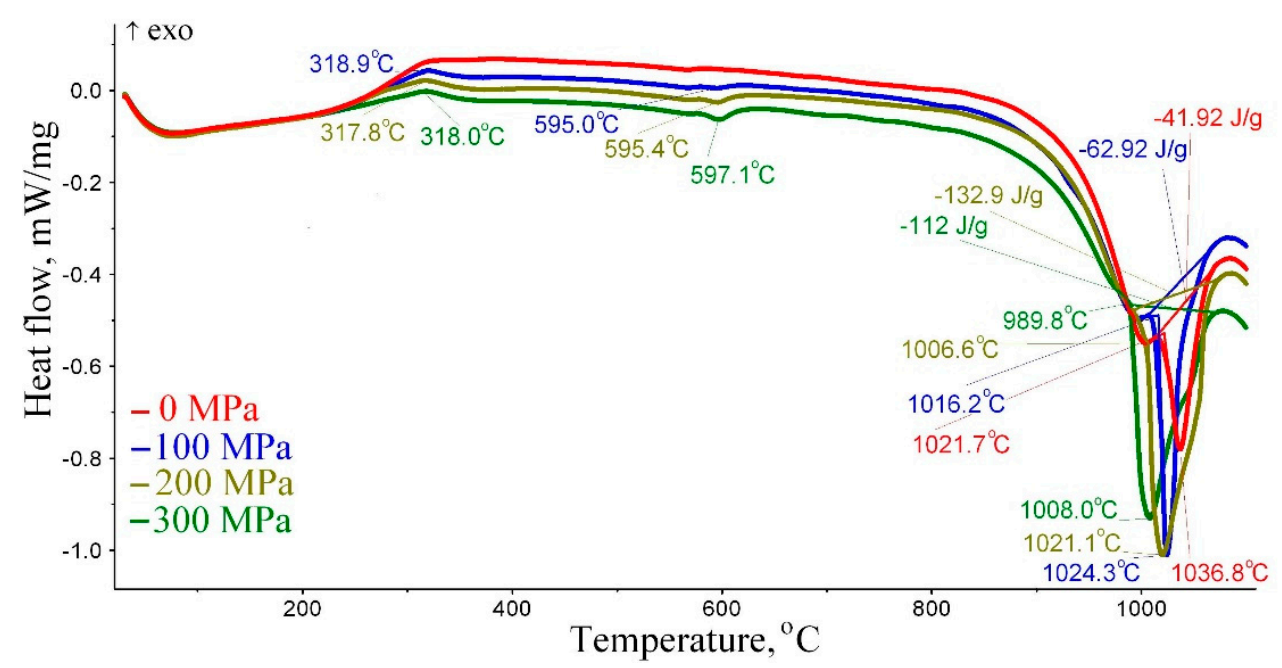

Figure 1. DSC data from of the pressed material mixture of rolled scale and coke without the flux.

Presented data shows that, at the temperature about $300{ }^{\circ} \mathrm{C}$, the processes of heat and mass transfer of reagents reach a value at which the DSC curves are ranked strictly in accordance with the pressure that the scale received during pressing. The DSC of nonpressed scale occupies the upper position and the pressed one at $300 \mathrm{MPa}$ occupies the lower position. The line for not-pressed scale is the upper and the line for scale, pressed at $300 \mathrm{MPa}$, is the lower. This indicates the pressing limiting influence on the process of studied mixture thermodynamic state converting. Due to a denser contact of the reacting phases, provided by increasing pressing pressure, the thermodynamic state of the mixture changes at the expense of less heat. At a temperature of about $600{ }^{\circ} \mathrm{C}$, a small endothermic effect is observed. It indicates the beginning of the $\mathrm{Fe}_{2} \mathrm{O}_{3}$ reduction process, according to Reaction (19), which is the first stage of the proposed scale reduction mechanism described below. According to thermodynamic calculations, this reaction is possible starting from the temperature of $539^{\circ} \mathrm{C}$.

$$
\mathrm{Fe}_{2} \mathrm{O}_{3}+\mathrm{C}=2 \mathrm{FeO}+\mathrm{CO} \uparrow
$$

Upon further heating at a temperature of about $1000^{\circ} \mathrm{C}$, a small endothermic effect is observed in the nonpressed and pressed scale at $100 \mathrm{MPa}$, indicating the end of the reducing process of $\mathrm{Fe}_{2} \mathrm{O}_{3}$ to $\mathrm{Fe}_{3} \mathrm{O}_{4}$ by Reaction (20) and reducing of $\mathrm{Fe}_{3} \mathrm{O}_{4}$ to $\mathrm{FeO}$ by Reaction (21):

$$
\begin{gathered}
2 \mathrm{FeO}+2 \mathrm{Fe}_{2} \mathrm{O}_{3}=2 \mathrm{Fe}_{3} \mathrm{O}_{4} \\
2 \mathrm{Fe}_{3} \mathrm{O}_{4}+2 \mathrm{C}=6 \mathrm{FeO}+2 \mathrm{CO} \uparrow
\end{gathered}
$$

Reactions (20) and (21) are the second stage of the proposed scale reduction mechanism.

DSC data also indicate that, with increasing pressing pressure, the enthalpy of formation of metallic iron and the rate of the reduction reaction increase. The change in these parameters depending on the pressing pressure is given in Table 4. 
Table 4. Change in the Metallic Iron Formation Beginning Temperature, the Value of the Endothermic Effect, and the Degree of Metallization of the First Series.

\begin{tabular}{cccc}
\hline $\begin{array}{c}\text { Pressing Pressure, } \\
\mathbf{M P a}\end{array}$ & $\begin{array}{c}\text { Temperature of the Metallic } \\
\text { Iron Formation Beginning, }{ }^{\circ} \mathbf{C}\end{array}$ & $\begin{array}{c}\text { Enthalpy of Metallic } \\
\text { Iron Formation, kJ/mol }\end{array}$ & $\begin{array}{c}\text { Metallization, } \\
\mathbf{\%}\end{array}$ \\
\hline 0 & 1021.7 & 2.3 & 34.6 \\
\hline 100 & 1016.2 & 3.5 & 49.6 \\
\hline 200 & 1006.6 & 7.8 & 66.9 \\
\hline 300 & 989.8 & 6.6 & 71.9 \\
\hline
\end{tabular}

In accordance with Table 4 , when the pressing pressure increases, the metallization beginning shifts to the lower temperature range from $1021.7^{\circ} \mathrm{C}$ at $0 \mathrm{MPa}$ to $989.8^{\circ} \mathrm{C}$ at $300 \mathrm{MPa}$.

As the pressing pressure increases, the enthalpy of metallic iron formation and the degree of metallization also increase. The enthalpy of iron metal formation increases from $2.3 \mathrm{~kJ} / \mathrm{mol}$ at $0 \mathrm{MPa}$ to $6.6 \mathrm{~kJ}$ at $300 \mathrm{MPa}$. The metallization degree increases from $34.0 \%$ to $72 \%$, respectively.

The data of comparative qualitative phase analysis of the pressed mixture without flux, heated in an argon atmosphere, are shown in Figure 2.

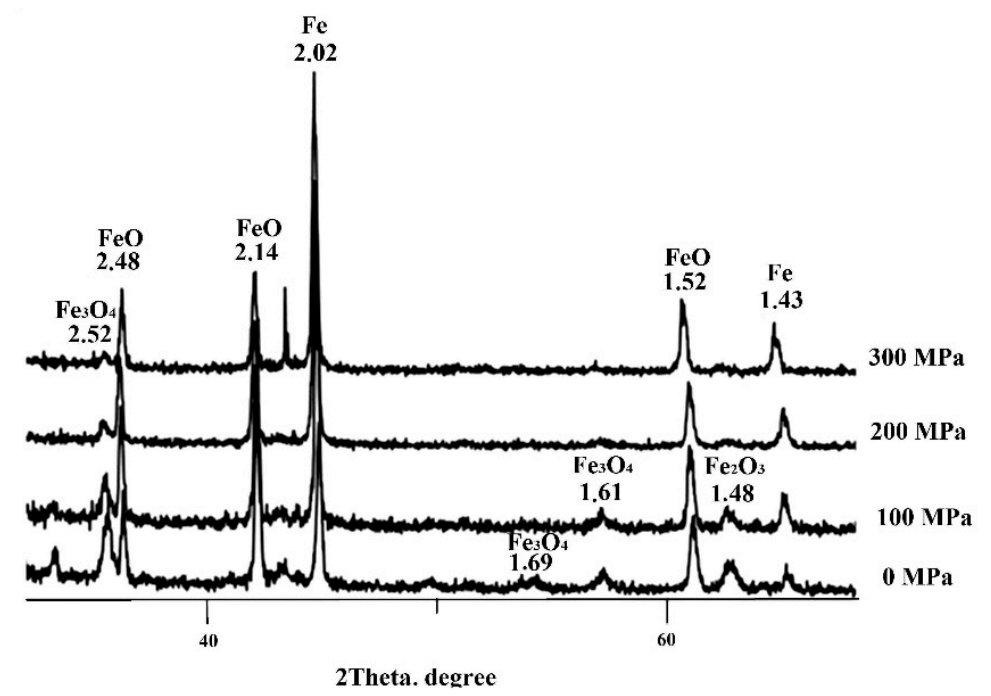

Figure 2. Influence of the pressing pressure of a raw mixture without flux heated in an argon medium on the change in its phase composition.

Table 5 shows the phase composition of the firing products according to quantitative phase analysis, depending on the pressing pressure.

Table 5. Firing Products' Phase Composition According to Quantitative Phase Analysis Depending on the Pressing Pressure.

\begin{tabular}{ccccc}
\hline \multirow{2}{*}{ Pressing Pressure of Scale with Coke, $\mathbf{M P a}$} & \multicolumn{4}{c}{ Content, Mass. \% } \\
\cline { 2 - 5 } & $\mathrm{Fe}_{\mathbf{2}} \mathbf{O}_{\mathbf{3}}$ & $\mathbf{F e}_{\mathbf{3}} \mathbf{O}_{\mathbf{4}}$ & $\mathbf{F e O}$ & $\mathbf{F e}_{\text {met }}$ \\
\hline 0 & 4.6 & 19.9 & 40.9 & 34.6 \\
\hline 100 & 3.2 & 14.5 & 32.7 & 49.6 \\
\hline 200 & 0 & 6.5 & 26.6 & 66.9 \\
\hline 300 & 0 & 4.5 & 23.5 & 72.0 \\
\hline
\end{tabular}

According to quantitative phase analysis, the residual content of $\mathrm{Fe}_{2} \mathrm{O}_{3}$ in the heating products of nonpressed scale and pressed at $100 \mathrm{MPa}$ is $4.6 \%$ and $3.2 \%$, respectively. There is no $\mathrm{Fe}_{2} \mathrm{O}_{3}$ in the 
heating products of scale pressed at 200 and $300 \mathrm{MPa}$. Thus, the phase data confirm the conclusions made after DSC analysis, that a small endothermic effect at a temperature of $1000{ }^{\circ} \mathrm{C}$ indicates the completion of the reducing process of $\mathrm{Fe}_{2} \mathrm{O}_{3}$ to $\mathrm{Fe}_{3} \mathrm{O}_{4}$. In addition, from the phase analysis data, it follows that under the same conditions of heat treatment, with an increase in the pressing pressure, the content of iron oxide phases decreases from $65.4 \%$ for nonpressed scale to $28.0 \%$ for scale pressed at $300 \mathrm{MPa}$. The content of metallic iron, on the contrary, increases.

Figure 3 presents DSC data of pressed mixture with $10 \%$ flux.

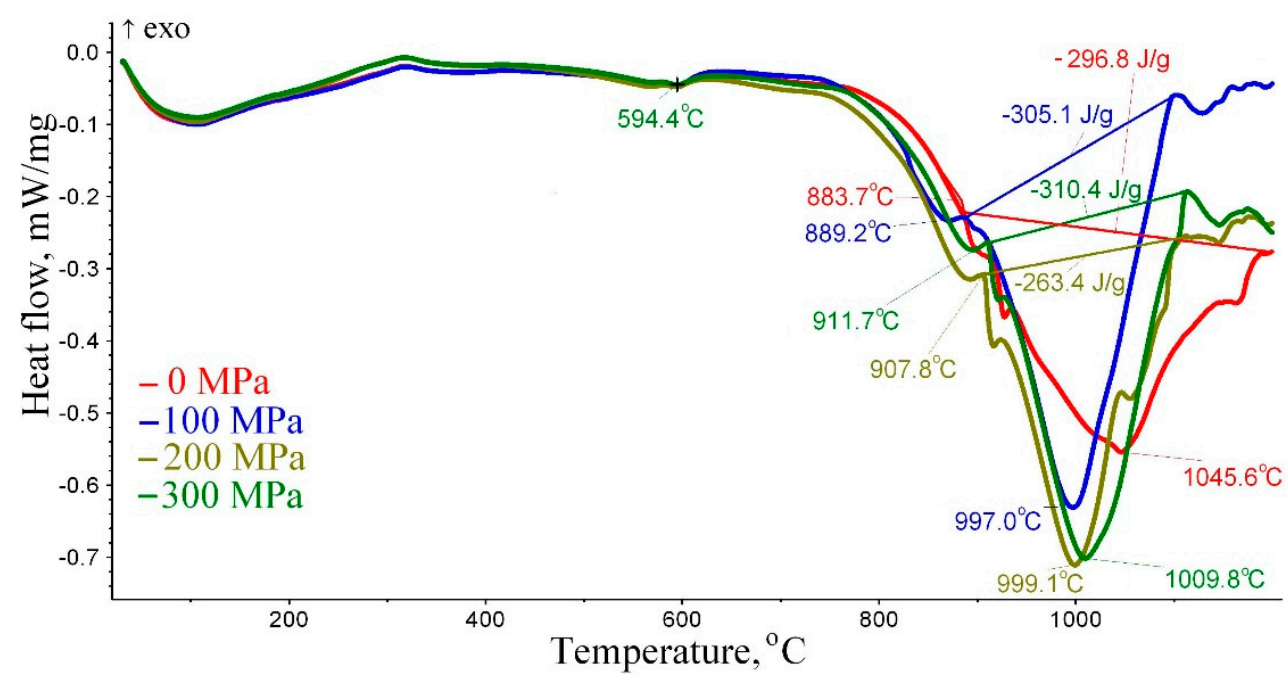

Figure 3. DSC data of the pressed mixture of scale and coke with the addition of $10 \%$ flux.

The DSC data presented in Figure 3 show that, at a temperature of $600{ }^{\circ} \mathrm{C}$, all four compositions have a small endothermic effect and the separation of the DSC curves depending on the pressing pressure also begins at this temperature. Small endothermic effects at a temperature of $1000{ }^{\circ} \mathrm{C}$ are observed in all compositions.

The change in the temperature of the metallic iron formation beginning and the third series endothermic effect value are shown in Table 6.

Table 6. Change in the Metallic Iron Formation Beginning Temperature, the Value of the Endothermic Effect, and the Degree of Metallization of the Third Series.

\begin{tabular}{cccc}
\hline $\begin{array}{c}\text { Pressing Pressure, } \\
\text { MPa. }\end{array}$ & $\begin{array}{c}\text { Temperature of the Metallic } \\
\text { Iron Formation Beginning, }{ }^{\circ} \mathbf{C}\end{array}$ & $\begin{array}{c}\text { Enthalpy of Metallic } \\
\text { Iron Formation, kJ/mol }\end{array}$ & $\begin{array}{c}\text { Metallization, } \\
\text { \% }\end{array}$ \\
\hline 0 & 883.7 & 16.6 & 69.3 \\
\hline 100 & 889.2 & 17.0 & 73.6 \\
\hline 200 & 907.8 & 14.7 & 64.3 \\
\hline 300 & 911.7 & 17.4 & 58.2 \\
\hline
\end{tabular}

According to the Table 6 , it can be seen that in the mixture containing flux, with increasing pressing pressure, the temperature of the metallic iron formation beginning rises from $883.7^{\circ} \mathrm{C}$ to $911.7^{\circ} \mathrm{C}$, the metal iron formation enthalpy increases slightly from $16.6 \mathrm{~kJ} / \mathrm{mol}$ at $0 \mathrm{MPa}$ to $17.4 \mathrm{~kJ} / \mathrm{mol}$ at $300 \mathrm{MPa}$, and the metallization degree even slightly decreases, respectively, from $69.3 \%$ to $58.2 \%$.

The data of comparative qualitative phase analysis of the pressed material mixture with $10 \%$ flux, during heating in an argon atmosphere, are shown in Figure 4. 


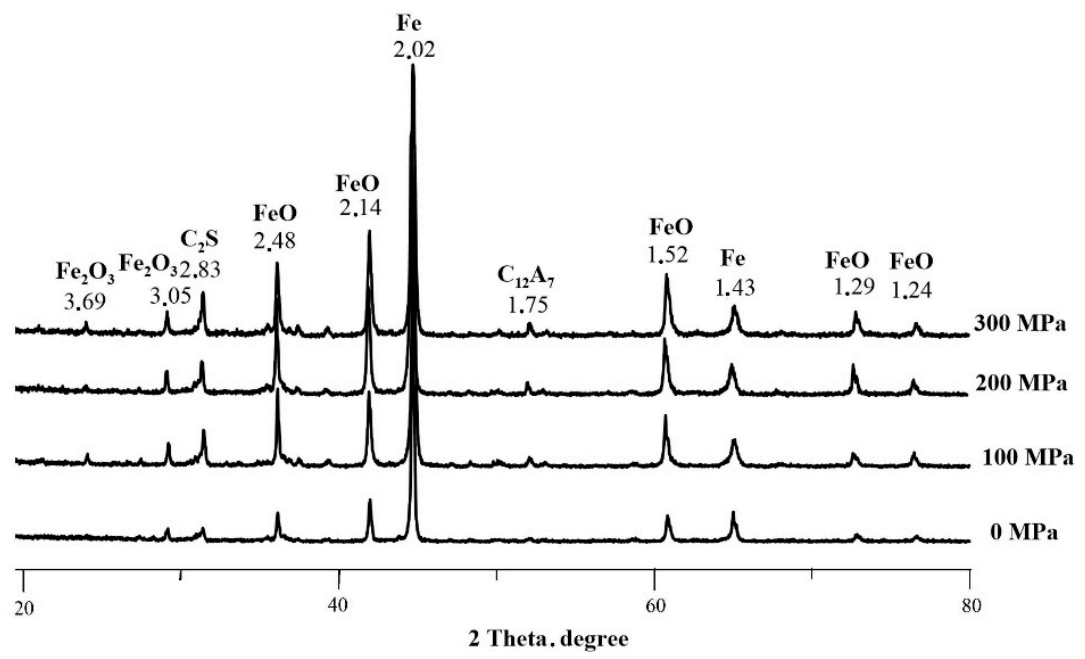

Figure 4. Pressing pressure of the materials' mixture containing flux effect on its phase composition change, during heating in an argon atmosphere.

Table 7 shows the phase composition of firing products with flux according to quantitative phase analysis depending on the pressing pressure.

Table 7. The Phase Composition of Firing Products with Flux According to Quantitative Phase Analysis Depending on the Pressing Pressure.

\begin{tabular}{|c|c|c|c|c|}
\hline \multirow{2}{*}{$\begin{array}{c}\text { Pressing Pressure of Scale with Coke and } \\
5 \% \text { Flux, MPa }\end{array}$} & \multicolumn{4}{|c|}{ Content, Mass. $\%$} \\
\hline & $\mathrm{Fe}_{2} \mathrm{O}_{3}$ & $\mathrm{Fe}_{3} \mathrm{O}_{4}$ & $\mathrm{FeO}$ & $\mathrm{Fe}_{\text {met }}$ \\
\hline 0 & 1.9 & 2.2 & 31.8 & 61.9 \\
\hline 100 & 1.8 & 2.5 & 26.9 & 66.4 \\
\hline 200 & 3.1 & 1.7 & 34.0 & 53.2 \\
\hline 300 & 2.5 & 0 & 41.4 & 46.9 \\
\hline
\end{tabular}

The phase analysis data show a small content of hematite and magnetite in the heating products of the mixture containing flux, and it practically does not change with increasing pressing pressure. The FeO content increases with increasing pressing pressure from $31.8 \%$ for nonpressed to $41.4 \%$ for pressed at $300 \mathrm{MPa}$ scale, and the content of metallic iron, on the contrary, decreases from $69.3 \%$ to $46.9 \%$, respectively.

According to the data presented in Figure 4 and Table 7, it can be seen that the pressing pressure does not significantly affect the measured parameters when the material mixture contains $10 \%$ of flux, in contrast to the material mixture that does not contain flux.

\section{Discussion}

The results of thermodynamic analysis show that the recovery of hematite, magnetite, and wustite above the temperature of $700{ }^{\circ} \mathrm{C}$ is possible through solid-phase interaction of reagents. Roasting of the mixture based on coke and scale in an argon atmosphere with the gaseous products' removal from the reaction zone, i.e., in conditions that exclude the participation of gaseous products in the recovery process, showed that the recovery processes are successfully implemented with a high degree of metallization through the solid phase.

To explain the observed effects, we propose an ion diffusion-catalytic mechanism of iron oxides' solid-phase reduction, detailing the provisions of the theory of V.E. Roshchin with colleagues [22-26] on the role of electronic processes in the iron oxides' reduction, adapted by us in relation to iron oxides of technogenic origin. 
According to this mechanism, at the first stage, the solid-phase interaction of the hematite located on the surface of the scale with the solid carbon located in the intergranular space occurs, with the formation of a CO by Reaction (19). As indicated above, this reaction is possible starting from the temperature of $539{ }^{\circ} \mathrm{C}$. The endothermic effect observed on the DSC curves at a temperature of $\approx 600^{\circ} \mathrm{C}$ corresponds to the beginning of the recovery first stage. In accordance with the statements of Roshchin's theory, the metallic iron crystal lattice is a crystal structure with cations at its nodes, and collectivized electrons fill the space between the cations and bind them to the backbone of the crystal lattice. When metal iron is oxidized, oxygen dissolves in it and adds its electronic shell with electrons, becoming an anion. The metal is transformed into a higher oxide after all collectivized electrons become bonded with anions. During reducing, reverse processes occur. Oxygen does not carry away the previously captured valence electrons when extracted from the scale surface due to intergrain carbon interaction, since this would disrupt the charges' balance in the oxide. In our opinion, it transfers electrons to neighboring iron cations. As a result, an oxygen vacuum is formed on the scale surface, two atoms of divalent iron and, respectively, two ionic crystals of wustite.

Resulting wustite are thermodynamically unstable, since they are thermodynamically predisposed to interact with the below hematite layers to form two magnetite molecules by the Reaction (20), which is the beginning of the recovery second stage. At $600{ }^{\circ} \mathrm{C}$, the Gibbs free energy of this reaction is $-58.4 \mathrm{~kJ} / \mathrm{mol}$. The end of the recovery second stage is the interaction of oxygen of newly formed magnetite molecules with solid intergranular carbon, with the formation of six $\mathrm{FeO}$ and $\mathrm{CO}$ molecules by Reaction (21). Small endothermic effects of $\approx 1000{ }^{\circ} \mathrm{C}$ correspond to the curves of this reaction, and they are observed only in mixtures with a sufficient amount of residual $\mathrm{Fe}_{2} \mathrm{O}_{3}$. The Reaction (21) is thermodynamically possible starting from a temperature of $700^{\circ} \mathrm{C}$. As a result of this reaction, oxygen will transfer electrons to neighboring iron atoms with the formation of six divalent iron atoms and the formation of two oxygen vacancies. The newly formed wustite molecules also will be associated with the remaining neighboring hematite molecules with the formation of magnetite molecules. Due to the formation of a wustite molecule's significant number, the catalytic acceleration of the scale reduction processes will occur with the promotion of divalent iron ions deep into the scale and oxygen anions to the surface, in the direction of oxygen vacancies. Due to the catalytic acceleration, provided by the wustite significant amount formation, at the third stage of reducing process, it is restored to metallic iron. At the final stage, only wustite molecules and oxygen vacancies will be located on the scale surface. The wustite oxygen interaction with solid carbon will lead to the metallic iron and CO formation by Reaction (12). According to thermodynamic calculations (Table 1), this reaction is possible from the temperature of $800^{\circ} \mathrm{C}$, and a large endothermic effect in the phase of the highest reaction speed corresponds to this reaction on all DSC curves. During the third stage, oxygen anions will move to the surface and the cations of metallic iron formed during this process will form an apparent flow of movement into the crystal.

The test results show that without the introduction of flux into the material mixture, the pressing pressure has a significant effect on the firing products' phase composition and the recovery process parameters. When the material mixture contains $10 \%$ flux, the pressing pressure effect on the firing products' phase composition and the recovery process parameters is minimal. These data indicate that when a sufficient amount of flux is introduced into mixture, the diffusion processes begin to prevail over the dense packing processes associated with pressing pressure. In other words, a sufficient mass of introduced flux eliminates a significant part of process diffusion difficulties, ensuring that the metallization beginning temperature is close to the minimum limit (due to thermodynamics). Also, we can say that the introduction of flux and pressing to some extent have an equivalent effect associated with an increase in the mobility of ions and the growth of the grains' active surface.

\section{Conclusions}

(1) Calculations of thermodynamic characteristics and experimental data on the interaction of scale and carbon oxides show the possibility of reducing iron from $\mathrm{Fe}_{2} \mathrm{O}_{3}$ oxide starting from a 
temperature of $700{ }^{\circ} \mathrm{C}$ and from $\mathrm{Fe}_{3} \mathrm{O}_{4}$ and $\mathrm{FeO}$ starting from a temperature of $800{ }^{\circ} \mathrm{C}$ without the participation of the gaseous phase. The reduction of iron from $\mathrm{Fe}_{3} \mathrm{O} 4$ and $\mathrm{FeO}$ oxides with the participation of the gas phase is thermodynamically impossible if the temperature is above $600{ }^{\circ} \mathrm{C}$.

(2) It was found that, in the absence of a liquid silicate phase, the pressing pressure has a significant effect on the iron oxides' reduction. An increase in the pressing pressure increases the metallization degree and shifts the metallization beginning to the lower temperatures.

(3) The flux introduction into the system leads to the formation of a liquid silicate phase (at the iron oxides' reduction temperatures). It changes the reduction mechanism. The liquid phase facilitates the processes of diffusion reduction of iron oxides. The pressing pressure in this connection almost has no effect on the temperature of recovery beginning and the metallization degree.

(4) It is shown that the flux mass (10 mass.\%) is sufficient to eliminate a significant part of the diffusion difficulties of the reduction process mechanism and it provides a thermodynamically optimal temperature for the beginning of metallization process.

(5) The ion diffusion-catalytic mechanism for scale iron oxides' solid-phase reduction is proposed. It details and clarifies the theory of V.E. Roshchin and colleagues in relation to iron oxides of technogenic origin.

(6) The proposed mechanism basis is the ions' diffusion in conditions of solid-phase reactions, and the catalytic acceleration of that reactions is provided by the avalanche-like appearance of a significant wustite amount.

Author Contributions: Conceptualization, M.M.; Investigation, L.V.; Supervision, O.S.; Writing-original draft, M.M.; Writing-review and editing, L.V., I.N., and D.E. All authors have read and agreed to the published version of the manuscript.

Funding: The reported study was funded by RFBR (Russian Foundation for Basic Research) according to the research project № 18-29-24064.

Conflicts of Interest: The authors declare no conflict of interest. The funders had no role in the design of the study; in the collection, analyses, or interpretation of data; in the writing of the manuscript; or in the decision to publish the results.

\section{References}

1. Hinton, J.; Lee, J. Key challenges for efficient descaling. AISTech. -Iron Steel Technol. Conf. Proc. 2020, 2, 1115-1125.

2. Kumar, D.S.; Sah, R.; Sekhar, V.R.; Vishwanath, S.C. Development and use of mill scale briquettes in BOF. Ironmak. Steelmak. 2017, 44, 134-139. [CrossRef]

3. Ma, N.; McDowell, B.J.; Houser, J.B.; Andrade, M.W.; Heinz, D.E. Separation of mill scale from flume wastewater using a dynamic separator toward zero wastes in the steel hot-rolling process. J. Sustain. Metall. 2019, 5, 97-106. [CrossRef]

4. Tirado González, J.G.; Reyes Segura, B.T.; Esguerra-Arce, J.; Castañeda, A.B.; Aguilar, Y.; Esguerra-Arce, A. An innovative magnetic oxide dicpersion-strenghened iron compound obtained from and industrial byproduct, with a view to circular economy. J. Clean. Prod. 2020, 268, 122362. [CrossRef]

5. Sanin, V.N.; Ikornikov, D.M.; Andreev, D.E.; Sachkova, N.V.; Yukhvid, V.I. Mill scale recycling by SHS metallurgy for production of cast ferrosilicon and ferrosilicoaluminium. IOP Conf. Ser. Mater. Sci. Eng. 2019, 558, 012041. [CrossRef]

6. Rodzevich, A.P. Physical and Chemical Bases of Metallurgical Processes: Educational Textbook; Yurginsk Institute of Technology: Tomsk, Russia, 2010.

7. Gerasimenko, A.A. Protection against Corrosion, Aging and Bio-Damage of Machinery, Equipment and Structures: Reference Book 1; Machine Engineering: Moscow, Russia, 1987.

8. Gorshkov, V.S.; Saveliev, V.G.; Fedorov, N.F. Physical Chemistry of Silicates and Other Refractory Compounds: Educational Textbook; Higher School: Moscow, Russia, 1988.

9. Gruner, L. Etudes sur les Hauts-Fourneaux: Suivies d'une Notice sur les Appareils à Air Chaud; Dunod: Paris, France, 1873. 
10. Rostovtsev, S.T.; Simonov, V.K. (Eds.) Mechanism of Carbon-Thermal Reduction of Metal Oxides. Mechanism and Kinetics of Metal Reduction; Science: Moscow, Russia, 1970.

11. Senin, A.V.; Pashkeev, I.Y.; Mikhalov, G.G. Gas-phase-solid-phase mechanism for recovery of ore materials. In Proceeding of the Prospects for the Development of Metallurgy and Mechanical Engineering Using Completed Basic Research and R\&D: FERROALLOYS, Ekaterinburg, Russia, 29 October-2 November 2018; pp. 72-80.

12. Tleugabulov, S.M.; Abikov, S.B. Fundamentals and prospects for the development of reduction steel melting. Metals 2018, 2, 72-77.

13. Averin, V.V.; Korneev, V.P.; Dybanov, V.G. Solid-phase carbon reduction of electric furnace sludges. Univ. Trans. Ferr. Metall. 2010, 9, 10-13.

14. Popel, S.I.; Sotnikov, A.I.; Boronenkov, V.N. Theory of Metallurgical Processes: Educational Textbook for Universities; Metallurgy: Moscow, Russia, 1986.

15. Chufarov, G.I.; Men, A.N.; Balakirev, V.F. Thermodynamics of Metal Oxide Reduction Processes; Metallurgy: Moscow, Russia, 1970.

16. Roshchin, V.E.; Roshchin, A.V. Electronic processes during metals recovery and extracting from ores. Electrometallurgy 2020, 3, 14-24.

17. Komatsu, W. Kinetics of solid-state reactions. In Proceedings of the 5th International Symposium on the Reactivity of Solids, Munich, Germany, 2-8 August 1964; Elsevier: Amsterdam, The Netherlands, 1965.

18. Baikov, A.A. Collection of Selected Works in 2 Books Book 2; AS USSR: Moscow-Leningrad, Russia, 1948.

19. Levitas, V.I. Continuum mechanical fundamentals of mechanochemistry. In High Pressure Surface Science and Engineering. Section 3; Gogotsi, Y., Domnich, V., Eds.; CRC Press: Boca Raton, FL, USA, 2003; pp. 161-292.

20. Drickamer, H.G.; Frank, C. Electronic Transitions and the High Pressure Chemistry and Physics of Solids; Chapman and Hall: London, UK, 1973.

21. Vedmid', L.B.; Mikheenkov, M.A.; Sheshukov, O.Y.; Nekrasov, I.V. Method for Briquetting Iron-Containing Wastes in Form of Scale. Patent RU № 2705483, 7 November 2019.

22. Roshchin, V.E.; Roshchin, A.V. Electron mechanism of reduction process in blast and ferroalloy furnaces. CIS Iron Steel Rev. 2019, 17, 14-24. [CrossRef]

23. Roshchin, V.E.; Roshchin, A.V. Physics of metals oxidation and reduction in the solid phase. Metals 2015, 3, 19-24. [CrossRef]

24. Roshchin, V.E.; Gamov, P.A.; Roshchin, A.V. Electronic recovery theory: Implications for the theory and practice of metals extracting from ores. Univ. Trans. Ferr. Metall. 2019, 62, 407-417.

25. Roshchin, V.E.; Roshchin, A.V.; Gamov, P.A.; Bilgenov, A.S. Electro-and mass transfer during the metals reduction by solid carbon in solid complex oxides. Metals 2020, 1, 33-37.

26. Roshchin, V.E.; Roshchin, A.V.; Berdnikov, A.A.; Goihenberg, U.N. Formation and sublimation of intermediate products of silicon reduction from its oxide. Metals 2008, 4, 14-18.

Publisher's Note: MDPI stays neutral with regard to jurisdictional claims in published maps and institutional affiliations.

(C) 2020 by the authors. Licensee MDPI, Basel, Switzerland. This article is an open access article distributed under the terms and conditions of the Creative Commons Attribution (CC BY) license (http://creativecommons.org/licenses/by/4.0/). 